\title{
THE DETERMINANT OF THE INCIDENT OF HYPERTENSION IN BALEKAMBANG HELATH CENTER, BENDUNGAN VILLAGE, JONGGOL SUB - DISTRIC, IN THE YEAR 2021
}

\author{
Wati Jumaiyah $^{1^{*}}$, Siti Latifah ${ }^{3}$ \\ 1. Faculty of Nursing, University of Muhammadiyah Jakarta, Jakarta -Indonesia \\ 2. Faculty of Nursing, University of Muhammadiyah Jakarta, Jakarta -Indonesia
}

*Correspondence: Wati Jumaiyah | University of Muhammadiyah Jakarta |watijumaiyah@umj.ac.id

\begin{abstract}
Introduction: Hypertension is a condition of high blood pressure and as The Silent Killer because most are asymptomatic or asymptomatic. sethat treatment is often too late. The incidence of hypertension is influenced by several factors, such as obesity (obesity), alcohol consumption, sodium intake, and stress. The purpose of this research is to find outdeterminants of the incidence of hypertension in Balekambang Health Center.

Method: This type of research is analytic observational using a cross sectional research design. The sampling technique used in this study is Probability Sampling with Simple Random Sampling with a total sample of 86 respondents using the chi square test.

Results: The results of this study are the majority of the respondents' ages are included in the early elderly, namely the age of 46-55 years (26.7\%), the most gender is female $(61.6 \%)$ and the majority have low education $(65.1 \%)$, the majority of respondents do not experience obesity (76.7\%), the majority of respondents do not consume alcohol $(81.4 \%)$, more respondents have high sodium intake $(59.3 \%)$ and the majority of respondents experience stress $(51.2 \%)$.

Conclusion: The conclusion of this study obtained that the factors associated with the incidence of hypertension are overweight/obesity $(\mathrm{p}$-value $=0.001)$, sodium intake $(\mathrm{p}$-value $=0.001)$, and stress $(\mathrm{p}$-value $=0.001)$. Meanwhile, there is no relationship between the incidence of hypertension and alcohol consumption ( $\mathrm{p}$-value $=0.055)$. Health services can improve health promotion efforts regarding prevention of hypertension cases through education to overcome obesity, alcohol consumption, high sodium intake and stress.
\end{abstract}

Keywords: Hypertension, Overweight (Obesity), Sodium Intake, Stress, Alcohol Consumption.

Received November 26, 2021; Accepted December 30, 2021

\section{INTRODUCTION}

The era of Indonesian globalization in the epidemiological transition phase has resulted in a shift in disease patterns from infectious diseases to non-communicable diseases, one of which is hypertension or often referred to as high blood pressure. Blood pressure is the power of blood to fight the pressure of the arterial walls when the blood is pumped by the heart throughout the body, the higher the blood pressure, the harder the heart works (AHA, 2020). The World Health Organization (2013) defines hypertension as a condition when blood vessels have high blood pressure, namely systolic blood pressure $140 \mathrm{mmHg}$ and diastolic blood pressure $90 \mathrm{mmHg}$ that persists.

The prevalence of hypertension varies across WHO regions and country income groups. hhypertension in low and middle income countries is an important problem that must be addressed immediately. In 2015 around 1.13 billion people in the world suffer from hypertension and it continues to increase every year, it is estimated that by 2025 there will be1.5 billion people affected by hypertension, so that one of the global targets for non-communicable diseases is to reduce the prevalence of hypertension by $25 \%$ in 2015. 2025 (WHO, 2019).

Hypertension is one of the main causes of mortality and morbidity in Indonesia, and based on the results of Riskesdas 2018 hypertension is ranked 1st of non-communicable diseases with a population of $63,309,620$ people with hypertension. The prevalence of hypertension in Indonesia based on the results of measurements on the population, the highest hypertension is in South Kalimantan (44.1\%), while the lowest prevalence is in Papua (22.2\%). In West Java Province, based on Riskesdas data in 2013 is the 4th province with the most cases of hypertension (29.4\%). Meanwhile, in 2018, West Java was in second place as the province with the highest hypertension cases in Indonesia, which was 39.6\% after South Kalimantan, 
which was $44.1 \%$ (Kemenkes RI, 2019). Hypertension is known as The Silent Killer because the majority are asymptomatic or asymptomatic.seuntil treatment is often too late (Kitt et al, 2019). Because the vast majority are asymptomatic, hypertension can be a risk factor for heart disease, kidney disease and stroke (WHO, 2013). PeHypertension causes high morbidity (illness) and mortality (death).Approximately 10.4 million deaths are caused by hypertension every year (AHA, 2020). Meanwhile, the death rate in Indonesia is 427,218 deaths caused by hypertension (Kemenkes RI, 2019).

Hypertension is a disease that arises due to the interaction of various risk factors that a person has (Octaviarini et al, 2019).Risk factors that can increase the incidence of hypertension include risk factors that cannot be changed and risk factors that can be changed. Risk factors that cannot be changed include family history, age, gender, and race. While the risk factors that can be changed are sodium intake, obesity (obesity), alcohol consumption, and stress (LeMone, et al., 2016). Natriun intake is one of the factors causing hypertension so that excessive sodium consumption causes the concentration of sodium in the extracellular fluid to increase to normalize the intracellular fluid being pulled out, so that the extracellular fluid volume increases. The increase in extra volume results in an increase in blood volume, thus having an impact on the onset of hypertension. It is recommended in consuming salt should not be more than 6 grams / day, equivalent to one teaspoon (Manurung, 2018). Being overweight (obesity) puts an extra strain on the heart and circulatory system, which can lead to serious health problems. It also increases the risk of high blood pressure (AHA, 2014).

Alcohol increases the acidity of the blood, making it thicker, and the heart is forced to pump blood. In addition, drinking alcohol increases the production of the hormone cortisol in the blood, which increases the activity of the renin- angiotensin aldosterone system (RAAS), which causes an increase in blood pressure (Jayanti, et al., 2017). Stress or mental pressure (stress, cases. For 2021, in January-March, 300 cases of hypertension have been recorded at the Balekambang Health Center. From the results of a preliminary study with interviews conducted by researchers on May 10, 2021 by interviewing 10 residents of the Dam village, it was found that 5 of them were hypertensive and 5 of them did not suffer from hypertension. 3 out of 5 people with hypertension like salty and 2 of them don't like salty while 1 out of 5 residents who don't suffer from hypertension like salty and 4 others don't like salty, 1 hypertensive patient out of 10 residents are overweight (obesity) and 9 of them are overweight normal, 1 hypertension sufferer from 10 residents consume alcohol and 9 of them do not consume alcohol, 5 hypertension sufferers experience stress and 3 others do not, while 5 residents who do not suffer from hypertension experience stress and 2 others do not. The average community in the Balekambang Community Health Center area likes salty on the grounds that eating without salted fish is incomplete and less enjoyable.

\section{METHOD}

This study is a quantitative research with an analytical observational type using a cross sectional research design to see the determinants of hypertension incidence at Balekambang Health Center in 2021. The sampling technique used in this study is Probability Sampling with Simple Random Sampling with a total sample of 86 respondents.

\section{RESULTS}

\section{Univariate Analysis Results}

Table 1 Distribution of Respondents Frequency by Age, Gender and Education at Balekambang Public

\begin{tabular}{|c|c|c|}
\hline \multicolumn{3}{|c|}{ Health Center in $2021(n=86)$} \\
\hline Variable & Frequency & Percentage (\%) \\
\hline \multicolumn{3}{|l|}{ Age } \\
\hline Late teens & 5 & 5.8 \\
\hline Early adulthood & 21 & 24.4 \\
\hline Late adult & 13 & 15.1 \\
\hline Early seniors & 23 & 26.7 \\
\hline Late seniors & 20 & 23.3 \\
\hline seniors & 4 & 4.7 \\
\hline Total & 86 & 100.0 \\
\hline
\end{tabular}




\begin{tabular}{lcc}
\hline Gender & & \\
Man & 33 & 38.4 \\
Woman & 53 & 61.6 \\
Total & 86 & 100.0 \\
Education & & \\
Low education & 56 & 65.1 \\
Higher education & 30 & 34.9 \\
Total & 86 & 100.0 \\
\hline
\end{tabular}

Age

Based on table 1, the results of the analysis of the majority of respondents' ages are early elderly, namely the age of $46-55$ years as many as 23 respondents (26.7\%).

\section{Gender}

Based on table 1, it was found that the data on the frequency distribution of respondents based on gender at the Balekambang Health Center were mostly female, as many as 53 respondents $(61.6 \%)$.

\section{Education}

Based on table 1, it was found that the data on the frequency distribution of respondents based on education at the Balekambang Health Center were mostly low-educated, namely 56 respondents $(65.1 \%)$.

Table 2 Distribution of Frequency Based on Independent Variables (overweight (obesity), alcohol consumption, sodium intake, stress) at Balekambang Public Health Center in $2021(n=86)$

\begin{tabular}{lcc}
\hline \multicolumn{1}{c}{ Variable } & Frequency & Percentage (\%) \\
\hline $\begin{array}{l}\text { Overweight (obesity) } \\
\text { Obesity }\end{array}$ & 20 & 23.3 \\
Not obese & 66 & 76.7 \\
Total & $\mathbf{8 6}$ & $\mathbf{1 0 0 . 0}$ \\
\hline Alcohol consumption & & \\
Consuming & 16 & 18.6 \\
Not consuming & 70 & 81.4 \\
Total & $\mathbf{8 6}$ & $\mathbf{1 0 0 . 0}$ \\
\hline Sodium intake & & \\
High sodium intake & 51 & 59.3 \\
Good sodium intake & 35 & 40.7 \\
Total & 86 & 100.0 \\
\hline Stress & & \\
Stress & 44 & 51.2 \\
No stress & 42 & 48.8 \\
Total & 86 & 100.0 \\
\hline
\end{tabular}

\section{Overweight (Obesity)}

Based on table 2., it was found that the data on the frequency distribution of respondents based on obesity (obesity) at the Balekambang Public Health Center were mostly non-obese, as many as 66 respondents $(76.7 \%)$.

\section{Alcohol Consumption}

Based on table 2., it was found that the data on the frequency distribution of respondents based on alcohol consumption at the Balekambang Public Health Center did not consume the majority, namely as many as 70 respondents $(81.4 \%)$.

\section{Sodium Intake}

Based on table 2, it was found that the data on the frequency distribution of respondents based on 
sodium intake at the Balekambang Public Health Center had a high sodium intake, namely 51 respondents $(59.3 \%)$.

\section{Stress}

Based on table 2, it was found that the data on the frequency distribution of respondents based on the stress category at the Balekambang Public Health Center were mostly stressed, namely 44 respondents $(51.2 \%)$.

Table 2 Distribution of Frequency Based on Dependent Variables (Hypertension Incidence) at Balekambang Public Health Center in $2021(\mathrm{n}=86)$

\begin{tabular}{lcc}
\hline \multicolumn{1}{c}{ Variable } & Frequency & Percentage (\%) \\
\hline Hypertension Incidence & & \\
Hypertension & 45 & 52.3 \\
No hypertension & 41 & 47.7 \\
Total & $\mathbf{8 6}$ & $\mathbf{1 0 0 . 0}$ \\
\hline
\end{tabular}

Based on table 3., it was found that the frequency distribution of respondents based on the incidence of hypertension in the Balekambang Public Health Center was the majority of hypertension, namely 45 respondents $(52.3 \%)$.

\section{Bivariate Analysis Results}

Table 4 Distribution of Respondents based on data on obesity (obesity), alcohol consumption, sodium intake, stress with hypertension incidence at Balekambang health center in $2021 \quad(n=86)$

\begin{tabular}{|c|c|c|c|c|c|c|c|c|}
\hline \multirow{3}{*}{ Variable } & \multicolumn{4}{|c|}{ Hypertension Incidence } & \multirow{2}{*}{\multicolumn{2}{|c|}{ Total }} & \multirow{3}{*}{ OR $(95 \% \mathrm{CI})$} & \multirow{3}{*}{$P$ Value } \\
\hline & \multicolumn{2}{|c|}{ Hypertension } & \multicolumn{2}{|c|}{$\begin{array}{c}\text { No } \\
\text { Hypertension }\end{array}$} & & & & \\
\hline & $\mathbf{n}$ & $\%$ & $\mathrm{n}$ & $\%$ & $\mathbf{N}$ & $\%$ & & \\
\hline \multicolumn{9}{|l|}{ Obesity } \\
\hline Obesity & 18 & 90.0 & 2 & 10.0 & 20 & 100.0 & \multirow{3}{*}{$13,000(2,784-60,705)$} & \multirow{3}{*}{0.001} \\
\hline No Obesity & 27 & 40.9 & 39 & 59.1 & 66 & 100.0 & & \\
\hline Total & 45 & 52.3 & 41 & 47.7 & 86 & 100.0 & & \\
\hline \multicolumn{9}{|c|}{ Alcohol Consumption } \\
\hline Consuming & 12 & 75.0 & 4 & 25.5 & 16 & 100.0 & \multirow{4}{*}{$3,364(0.988-11.451)$} & \multirow{3}{*}{0.055} \\
\hline Not Consuming & 33 & 47.1 & 37 & 52.9 & 70 & 100.0 & & \\
\hline Total & 45 & 52.3 & 41 & 47.7 & 86 & 100.0 & & \\
\hline \multicolumn{8}{|l|}{ Sodium Intake } & \\
\hline High sodium intake & 39 & 76.5 & 12 & 23.5 & 51 & 100.0 & \multirow{3}{*}{$15.708(5,274-46,790)$} & \multirow{3}{*}{0.001} \\
\hline Good sodium intake & 6 & 17.1 & 29 & 82.9 & 35 & 100.0 & & \\
\hline Total & 45 & 52.3 & 41 & 47.7 & 86 & 100.0 & & \\
\hline \multicolumn{9}{|l|}{ Stress } \\
\hline Stress & 33 & 75.0 & 11 & 25.0 & 44 & 100.0 & \multirow{3}{*}{$7,500(2,883-19,508)$} & \multirow{3}{*}{0.001} \\
\hline No stress & 12 & 28.6 & 30 & 71.4 & 42 & 100.0 & & \\
\hline Total & 45 & 52.3 & 41 & 47.7 & 86 & 100.0 & & \\
\hline
\end{tabular}

\section{Distribution of Respondents Based on Overweight (Obesity) Data with Hypertension Incidence at} Balekambang Public Health Center

Table 4. shows that the results of the analysis of the relationship between obesity and the incidence of hypertension at the Balekambang Public Health Center of 86 respondents, there were 18 respondents (90.0\%) who had a BMI >25 with hypertension and 2 respondents $(10.0 \%)$ did not have hypertension, while who have a BMI 25 there are 27 respondents (40.9\%) with hypertension and 39 (59.1\%) without hypertension.

Based on the results of statistical tests using the Chi-Square test, $\mathrm{p}$ value $=0.001$ ( $\mathrm{p}$ value $<0.05$ ) it can be concluded that there is a significant relationship between obesity and the incidence of hypertension in Balekambang Public Health Center, because $\mathrm{p}$ value < . In addition, from the statistical test results obtained 
$\mathrm{OR}=13,000$, meaning that respondents who have a BMI $>25$ have a 13 times higher chance of experiencing hypertension compared to respondents who have a BMI 25.

\section{Distribution of Respondents Based on Alcohol Consumption Data with Hypertension Incidence at Balekambang Public Health Center}

Table 4. shows that the results of the analysis of the relationship between alcohol consumption and The incidence of hypertension in the Balekambang Public Health Center of 86 respondents, there were 12 respondents $(75.0 \%)$ who consumed alcohol with hypertension and 4 respondents $(25.0 \%)$ did not have hypertension, while those who did not consume alcohol there were 33 respondents $(47.1 \%)$ with hypertension. hypertension and 37 respondents (52.9\%) were not hypertensive. Based on the results of statistical tests using the Chi-Square test, the $\mathrm{p}$ value $=0.055$ ( $\mathrm{p}$ value $<0.05$ ) then it can be it was concluded that there was no significant relationship between alcohol consumption and the incidence of hypertension at the Balekambang Public Health Center, because $\mathrm{p}$ value $>$. In addition, the statistical test results obtained $\mathrm{OR}=3.364$, meaning that respondents who consume alcohol have a 3 times higher chance of experiencing hypertension compared to respondents who do not consume alcohol.

\section{Distribution of Respondents Based on Data on Sodium Intake with Hypertension Incidence at Balekambang Public Health Center}

Table 4. shows that the results of the analysis of the relationship between sodium intake and the incidence of hypertension at the Balekambang Public Health Center of 86 respondents, there are 39 respondents $(76.5 \%)$ who have high sodium intake with hypertension and 12 respondents $(23.5 \%)$ do not have hypertension, while who have good sodium intake there are 6 respondents (17.1\%) with hypertension and 41 respondents $(82.9 \%)$ without hypertension.

Based on the results of statistical tests using the Chi-Square test, $\mathrm{p}$ value $=0.001$ ( $\mathrm{p}$ value $<0.05$ ) it can be concluded that there is a significant relationship between sodium intake and the incidence of hypertension in Balekambang Public Health Center, because $\mathrm{p}$ value <. In addition, the statistical test results obtained $\mathrm{OR}=15,708$, meaning that respondents with high sodium intake had a 15 times higher chance of experiencing hypertension compared to respondents with good sodium intake.

\section{Distribution of Respondents Based on Stress Data with Hypertension Incidence at Balekambang Public Health Center}

Table 4. shows that the results of the analysis of the relationship between stress and the incidence of hypertension at the Balekambang Public Health Center of 86 respondents, there are 33 respondents (75.0\%) who are stressed with hypertension and 11 respondents $(25.0 \%)$ are not hypertension, while those who are not stressed there are 12 respondents (28.6\%) had hypertension and 30 respondents $(71.4 \%)$ did not.

Based on the results of statistical tests using the Chi-Square test, $\mathrm{p}$ value $=0.001$ ( $\mathrm{p}$ value $<0.05$ ) it can be concluded that there is a significant relationship between stress and the incidence of hypertension in Balekambang Public Health Center, because $\mathrm{p}$ value < . In addition, the statistical test results obtained OR $=7,500$, meaning that respondents who are stressed have a 7 times higher chance of experiencing hypertension compared to respondents who are not stressed.

\section{DISCUSSION}

\section{Respondent's identity characteristics}

Age

The results of the study show that the majority of respondents' ages are early elderly, namely 46-55 years old, where at that age the sensitivity of blood pressure regulation, namely the baroreceptor reflex, begins to decrease so that it can trigger hypertension (Noerinda, 2018). Age is a characteristic that plays a role in the incidence of hypertension. This is because with age, blood vessels gradually lose their elasticity, which can cause an increase in blood pressure (AHA, 2014).

The results of this study are in agreement with several previous studies. Dinda Asa's research (2020), shows that age is a risk factor associated with hypertension. The results of this study are also in line with the results of Riskesdas 2018 which showed that blood pressure increased significantly by age group starting from the age of 45 years (Riskesdas, 2018). 


\section{Gender}

The results showed that most of the respondents in this study were female. In theory, men are at high risk of hypertension compared to women because the stressor factor that triggers hypertension in men is higher, and before entering menopause women are protected from cardiovascular disease because they have the hormone estrogen which plays a role in increasing levels of High Density Lipoprotein (HDL). ). High HDL cholesterol levels are a protective factor in preventing the process of atherosclerosis (Kusumawaty, et al., 2016). This is in line with research by Fatharani et al (2018), which shows that female respondents have a higher chance of experiencing hypertension than male respondents.

The researcher's analysis in this study showed that female respondents experienced more incidence of hypertension because from the results of the study the majority of respondents' ages were early elderly, namely 46-55 years old where at that age women experienced estrogen production which began to decrease so that the incidence of hypertension was higher than men.

\section{Education}

The results showed that the most recent education of respondents was the low level of education as many as 56 respondents $(65.1 \%)$ where one's knowledge influenced the understanding of hypertension prevention behavior, the better one's understanding of the causes of hypertension, risk factors, signs and symptoms, blood pressure normal and abnormal, the individual will avoid things that will trigger hypertension such as smoking, drinking coffee, obesity and others (Sinuraya et al, 2017).

knowledge is lacking and the level of awareness to continue education is still low, information and so on are still limited. This is also due to the fact that the majority of respondents are early elderly.

\section{The relationship between obesity (obesity) and the incidence of hypertension}

The results showed that there was a significant relationship between obesity (obesity) and the incidence of hypertension. Overweight (obesity) is the accumulation of excessive fat that can interfere with health. Excessive body weight makes it difficult for a person to move freely, so it can cause the heart to have to work harder to pump blood and can cause an increase in cardiac output so that blood pressure increases (Black and Hwaks, 2014).

This is in line with the research of Noerita Ridhasta Dewi (2018), which found that there was a relationship between obesity and the incidence of hypertension.

Researcher's analysis shows that the education of respondents in this study is mostly low-educated where the diet of respondents whose respondents do not understand the content of balanced nutrition, so they eat more high- carbohydrate foods. Snacks that are often eaten, such as cassava and tubers, can increase weight if consumed too often.

\section{The relationship between alcohol consumption and the incidence of hypertension}

The results showed that there was no significant relationship between alcohol consumption and the incidence of hypertension at the Balekambang Public Health Center. Alcohol is one of the causes of hypertension because it has the same effect as carbon dioxide which can also increase the acidity of the blood so that it causes the blood to become thick and the heart is forced to pump faster, resulting in an increase in blood pressure (Jayanti, et al., 2016).

This is in line with Herman Nur's research in (2016), with the results that there is no relationship between alcohol consumption and the incidence of hypertension in the work area of the Bulu Health Center, Sukoharjo Regency.

Research analysis shows that respondents at Balekambang Public Health Center are more dominant in women so that many do not consume alcohol and for male respondents, most of them are elderly so that most of the respondents have never consumed alcohol and some respondents have consumed alcohol at a young age. So this causes the research results between alcohol consumption and the incidence of hypertension in the Balekambang Health Center in 2021 to be unrelated.

\section{The relationship between sodium intake and the incidence of hypertension}

The results showed that there was a significant relationship between sodium intake and the incidence of 
hypertension. In theory, sodium intake plays a role in increasing blood pressure, so consuming high amounts of sodium and lack of potassium intake can result in an increase in blood pressure (WHO, 2020).

This study is in line with related research conducted by Ayu Fitri (2017) the results show that there is a significant relationship between salt consumption and the incidence of hypertension.

The analysis of the researchers in this study was that respondents from the Balekambang Community Health Center used salted fish as a side dish for their daily diet and respondents were more dominant in consuming salty food, which if the respondent consumed high levels of sodium it could increase the concentration of extracellular sodium, sodium would be excreted through the kidneys, if the excretion is high. exceeds the threshold, the kidneys will retain $\mathrm{H} 2 \mathrm{O}$ to neutralize sodium in the vasculature until the increase in the volume of intravascular fluid will increase blood pressure.

Most respondents from Balekambang Public Health Center have low education and many do not go to school, causing their lack of knowledge about good sodium intake or a good diet so that there is a relationship between sodium intake and the incidence of hypertension at Balekambang Health Center in 2021.

\section{The relationship between stress and the incidence of hypertension}

The results showed that there was a significant relationship between stress and the incidence of hypertension. As stress is a condition in which the body produces more adrenaline, it makes the heart work stronger and faster. If it occurs for a long time, it will cause a reaction in other body organs. Functional changes in blood pressure by stressful conditions can cause cardiovascular hypertrophy (Lawson, 2015).

This is in line with the research of Asfri Sri et al (2019), with the results of the study it is known that there is a significant relationship between stress and the incidence of hypertension.

The researcher's analysis in this study is that respondents in this area include respondents with low education, the majority of whom are farm laborers with low incomes, even because of this pandemic, many cannot work, so many complain of stress due to lack of income, and the stress can trigger the hormones adrenaline and hydrocortisone, if excessive and lasts for a long time can cause high blood pressure.

\section{CONCLUSION}

Based on the results of this study, it was found that there was a significant relationship between obesity (obesity) and the incidence of hypertension at the Balekambang Health Center, there was a significant relationship between sodium intake and the incidence of hypertension at the Balekambang Public Health Center, there was a significant relationship between stress and the incidence of hypertension at the Balekambang Public Health Center and there was no significant relationship between stress and hypertension. There is a significant relationship between alcohol consumption and the incidence of hypertension at the Balekambang Public Health Center. The frequency distribution of characteristics in respondents at the Balekambang Public Health Center is the majority of the early elderly aged 46-55 years, the sex is mostly female and the majority of respondents have low education.

\section{REFERENCE}

American Heart Association (AHA). 2020. International Society of Hypertension Global Hypertension Practice Guidelines. (On line) https://www.ahajournals.org/doi/epub/10. 1161/HYPERTENSIONAHA.120.15026

American Heart Association (AHA). 2014. Know Your Risk Factors For High Blood Pressure. America: $\begin{array}{ll}\text { American Heart Association (Aha). Retrieved } & \end{array}$

FromHttp://Heart.Org/En/Health- Topics/High-Blood-Pressure/Why-High- Bloodpressure-Is-A-SilentKiller/Know- Your-Risk-Factors-For-High-Blood- Pressure

Ayu F, Atih S. 2017. The relationship of modifiable factors with the incidence of hypertension in the West Pademangan II Public Health Center in 2017. Universitas Muhammadiyah Jakarta

Black. JM and Hwaks, JH 2014. Medical Surgical Nursing: Clinical Management for Expected Outcomes. Loaded fromhttps://booksgoogle.co.id/books?id=n wKcAQAAACAAJ

Dinda Asa, A. 2020. Risk Factors for Hypertension in Coastal Areas (Study in the Uptd Work Area of Tanjung Tiram Health Center). North Sumatra University

ISH. 2020. ISH Global Hypertension Practice Guidelines. 
KEMENKES (Ministry of Health) RI. 2013. Basic Health Research (RISKESDAS) 2013. Jakarta: Ministry of Health RI.

KEMENKES (Ministry of Health) RI. 2018. Obesity Classification after BMI measurement - Directorate of P2PTM (kemkes.go.id)

KEMENKES (Ministry of Health) RI. 2018. How to calculate BMI (Body Mass Index)-Directorate of P2PTM (kemkes.go.id)

KEMENKES (Ministry of Health) RI. 2019. Ministry of Health of the Republic of Indonesia (kemkes.go.id)

Kitt, J., Fox, R., Tucker, KL, \& McManus, RJ 2019. New approaches in hypertension management: a review of current and developing technologies and their potential impact on hypertension care. Current hypertension reports

LeMone, et.all. 2016. Medical surgical nursing textbook. EGC, Jakarta

Noerinda, R. 2018. Factors Affecting the Incidence of Hypertension in the Elderly in Manisrejo Village, Madiun City. Bhakti Husada Mulia

Noerinda, R. 2018. Factors Affecting the Incidence of Hypertension in the Elderly in Manisrejo Village, Madiun City. Bhakti Husada Mulia

Notoatmodjo, Sukidjo. 2012. Health Research Methodology. Jakarta: Rineka Cipta

Nursalam. 2017. Research Methodology in Nursing. Jakarta: Salemba Medika

Oktaviarini E. Hadisaputro S, Ari Suwando, Henry Setyawan. 2019. Risk factors for hypertension in employees in the Port Perimeter area (Study at the Class II Semarang Port Health Office). Journal of Community Health Epidemiology.

WHO. 2013. a global brief hypertension silent killer, global public health crisis. World Health Organization.(Online)https://apps.who.int/iris/bitstream/handle/10665/79059/WHO_DCO_WHD_2 013.2_eng.pdf;jsessionid=6BCD810D2D731FC72B8A7BB27E2A5FE0? sequence $=1$

WHO. 2019. Hypertension. World Health Organization. Loaded in https://www.who.int/news-room/factsheets/detail/hypertension 